\title{
Experience with Intravitreal Ranibizumab as an Adjunct to Ablation Therapy in Eyes with Exudative Coats' Disease
}

\author{
Mohamed Nowara ${ }^{1,2}$ \\ Yousef A Fouad (D) 1,3 \\ Ihab Abdel Aziz 1,4 \\ Ahmed M Habib (D) ${ }^{1,3}$ \\ Mariam Al-feky ${ }^{1,3}$ \\ Hisham Hassan' \\ 'Al Mashreq Eye Center, Cairo, Egypt; \\ ${ }^{2}$ Department of Ophthalmology, \\ Electricity Hospital, Cairo, Egypt; \\ ${ }^{3}$ Department of Ophthalmology, Ain \\ Shams University Hospitals, Cairo, Egypt; \\ ${ }^{4}$ Memorial Institute for Ophthalmic \\ Research, Giza, Egypt
}

This article was published in the following Dove Press journal: Clinical Ophthalmology

Background: Coats' disease is a rare entity with retinal vascular telangiectasia that can progress to exudative retinal detachment, neovascular glaucoma, and a blind painful eye requiring enucleation. Despite recent therapeutic advances decreasing the need for enucleation, no consensus exists about the optimum management of exudative Coats' disease. The use of intravitreal anti-vascular endothelial growth factor agents as an adjunct to ablation therapy has been shown to achieve favorable outcomes, but some reports suggest an increased incidence of vitreoretinal (VR) fibrosis and tractional retinal detachment (TRD).

Methods: We retrospectively reviewed records of patients presenting with exudative Coats' disease (stages 2 and 3) from April 2016 till November 2020. Extracted data included clinical and radiological assessment, stage (Shields' classification), interventions, and followup.

Results: Sixteen eyes were included in the final analysis, of which $4(25 \%)$ were stage 2 and $12(75 \%)$ were stage 3 . All eyes underwent intravitreal ranibizumab injection combined with ablation therapy, 14 (87.5\%) underwent cryotherapy, 4 (25\%) underwent laser ablation, 3 (18.75\%) underwent external subretinal fluid drainage, and $3(18.75 \%)$ underwent buckle or vitrectomy surgery. After a median follow-up of 16 months, 11 eyes $(68.75 \%)$ had complete resolution, 4 (25\%) had incomplete resolution, and only one $(6.25 \%)$ progressed but did not require enucleation. Three eyes (18.75\%) developed VR fibrosis, but none progressed to TRD.

Conclusion: Combining intravitreal ranibizumab injection with ablation therapy is effective in managing exudative Coats' disease. External drainage should be preserved for when ablation therapy is not feasible. Future prospective trials with pre-defined outcomes are required.

Keywords: Coats' disease, Leber's miliary aneurysms, exudative retinal detachment, vascular endothelial growth factor, cryotherapy

\section{Introduction}

Coats' disease is an idiopathic retinal telangiectasia commonly associated with intraretinal or subretinal exudation that may lead to exudative retinal detachment (ERD). ${ }^{1}$ Despite the low estimated incidence of 0.09 per 100000 of the population, ${ }^{2}$ progression to advanced stages can lead to detrimental complications including neovascular glaucoma $(\mathrm{NVG})$ and phthisis bulbi with a blind eye that may require enucleation. ${ }^{3}$ The disease is believed to be congenital but non-familial with a classic predilection towards unilateral presentation in young males, ${ }^{3}$
Correspondence: Yousef A Fouad Department of Ophthalmology, Ain Shams University Hospitals, Ramses Street, II5I7 Abbasiya, Cairo, Egypt Tel +20I06378I 237

Email yousef.a.fouad@gmail.com 
although the bilaterality of the condition has recently been suggested with the imaging of subtle vascular abnormalities in the fellow eye. ${ }^{4}$ Classification is based on morphology, with Shields' classification ${ }^{5}$ being the most commonly utilized.

Advances in managing the early stages of the condition have led to more favorable outcomes and greater globe salvage. In a recent analysis ${ }^{6}$ of the largest dataset of Coats' disease to date, significantly decremental enucleation rates were reported every decade onwards from the 1980 s till the 2010s, reflecting more effective halting of disease progression. Current options for managing exudative stages 2-4 of the condition (since stage 1 is pre-exudative and stage 5 is end-stage with non-salvageable globe ${ }^{5}$ ) include ablation therapy to the leaking vessels with cryo-application or laser thermal energy, intravitreal injection of antivascular endothelial growth factor (anti-VEGF) or steroids, surgical subretinal fluid (SRF) drainage, and retinal detachment surgery (buckle procedure or plans plana vitrectomy [PPV]) for advanced disease. ${ }^{1,3}$ However, the optimum therapeutic modality - or combination of modalities remains controversial with variable reports in the literature depicting inconsistent results. ${ }^{7}$

The demonstration of elevated VEGF levels in eyes with Coats' disease ${ }^{8}$ has supported the recent use of antiVEGF agents in the management of exudative stages of the condition. ${ }^{1}$ The adjuvant intravitreal injection of antiVEGF agents in combination with ablation treatment in even the advanced cases has been reported to achieve favorable outcomes with retinal flattening and macular dryness. $^{9,10}$ On the contrary, there have been reports ${ }^{11,12}$ cautioning against the off-label usage of anti-VEGF agents in Coat's disease, linking the injections to increased incidence of vitreoretinal (VR) fibrosis and risk of tractional retinal detachment (TRD) when combined with ablation therapy, particularly cryotherapy. ${ }^{7}$

In this work, we report our single-center experience with exudative Coats' disease including patient characteristics, presentation, and outcomes of management with the use of adjuvant anti-VEGF injection (ranibizumab).

\section{Methods}

This retrospective analysis involved reviewing the electronic medical records of patients diagnosed with exudative Coats' disease with a Shields' classification ${ }^{5}$ of stage 2 (hard exudates), 3 (ERD), or 4 (ERD with NVG) at a single private eye center, Almashreq Eye Center, from April 2016 until November 2020. The study adhered to the tenets of the Declaration of Helsinki and ethical review committee approval was obtained. Informed consents from patients were not required as the data were deidentified.

Data regarding patients' demographics, systemic associations and investigations, details of each visit including corrected distance visual acuity (CDVA) using Snellen chart, intraocular pressure (IOP) measurements (by Goldmann applanation or Perkins tonometer for younger patients) and imaging, follow-up duration, and disease stage were extracted from the records. Colored fundus photographs, fundus fluorescein angiography (FFA) images, optical coherence tomography (OCT) scans, and ultrasonography B-scans were reviewed to validate the diagnosis, extent, and staging of the disease. Nonsurgical and surgical interventions undergone by each patient were also recorded; surgical details were validated from operative room records. For younger patients who could not undergo office examination, details of examination under anesthesia in the operative room and recorded RetCam media were obtained and reviewed.

Anatomical and visual outcomes of the interventions were analyzed. Complete resolution was defined in stage 2 as disappearance of telangiectasia (evaluated clinically and confirmed by FFA imaging) and progressive reduction in exudate load, and in stage 3 as complete resolution of SRF with flattening of the retina (evaluated clinically and confirmed by OCT imaging). Partial resolution in stage 3 was defined as reduction - but not disappearance - of SRF or intraretinal macular edema. Progression was defined as higher disease stage recorded during follow-up. Stable condition was defined as non-progression over a period of at least 6 months. Complication rates were also recorded.

Data were tabulated in Excel (Microsoft, United States) and imported to SPSS v25 (IBM, United States) to perform statistical analysis.

\section{Results}

We identified 19 eyes of 19 patients with Coats' disease from our search of the records. One eye was excluded from analysis due to wrong diagnosis, and 2 eyes were excluded due to missing follow-up data. Of the 16 remaining patients, $11(68.75 \%)$ were males and 5 (31.25\%) were females. The median age at presentation was 5 years (range: $0.5-17$ years). Fifteen patients (93.75\%) had no systemic association. The remaining patient $(6.25 \%)$ had Parry-Romberg syndrome, a form of idiopathic hemifacial atrophy. 
The initial complaint by the patients or their caregivers was eye deviation (43.75\%), progressive diminution of vision in the affected eye (37.5\%), and a white pupil $(18.75 \%)$. Of the nine patients $(56.25 \%)$ whose age allowed vision assessment, CDVA in the affected eye was less than $20 / 400(0.05)$ in four patients (44.44\%), 20/400 (0.05) in two patients $(22.22 \%), 20 / 200(0.1)$ in one patient $(11.11 \%)$, $20 / 100(0.2)$ in one patient (11.11\%), and 20/20 (1.0) in one patient $(11.11 \%)$. The median (range) IOP at the initial visit was 17 (9-21) mmHg. The other eye was healthy in 14 patients $(87.5 \%)$, lost due to advanced congenital glaucoma in 1 patient (6.25\%), and impaired with 20/63 (0.32) vision due to priorly managed rhegmatogenous detachment (RRD) in 1 patient $(6.25 \%)$.

Four patients (25\%) had Shields' stage 2 disease, with two of them having extrafoveal exudation $(2 \mathrm{~A}, 12.5 \%)$, and two having foveal exudation (2B, 12.5\%, Figure 1A). Twelve patients (75\%) had stage 3 disease, seven (43.75\%) had subtotal ERD (stage 3A) that was extrafoveal (3A1, Figure $1 \mathrm{~B})$ in five patients $(31.25 \%)$ and involved the fovea (3A2, Figure 1C) in two patients (12.5\%), while five patients $(31.25 \%)$ had total ERD (stage 3B, Figure 1D). Thirteen eyes (81.25\%) underwent serial FFA and 14 eyes (87.5\%) underwent serial OCT imaging.

Table 1 demonstrates the interventions and outcomes of the patients in the different disease stages. All cases (100\%) underwent off-label intravitreal injection of the anti-VEGF agent ranibizumab with a dose of $0.5 \mathrm{mg} / 0.05 \mathrm{~mL}$ and a median of 1 injection (range: 1-3). All patients underwent injection as the initial intervention, with 12 cases (75\%) undergoing simultaneous ablation therapy. Fourteen cases (87.5\%) underwent cryotherapy while 4 cases $(25 \%)$ underwent laser therapy (with two eyes undergoing both ablation modalities). Re-treatment was required in four patients (25\%) who had no response or partial resolution. External SRF drainage was required in three cases $(18.75 \%)$ for effective application of cryotherapy. Of those, one eye (33.33) had an iatrogenic break complicating the drainage and a PPV was performed to flatten the retina.

The median duration of follow-up was 16 months (range: 6-48 months). Stable disease was seen in 15 patients $(93.75 \%)$, and only one patient $(6.25 \%)$

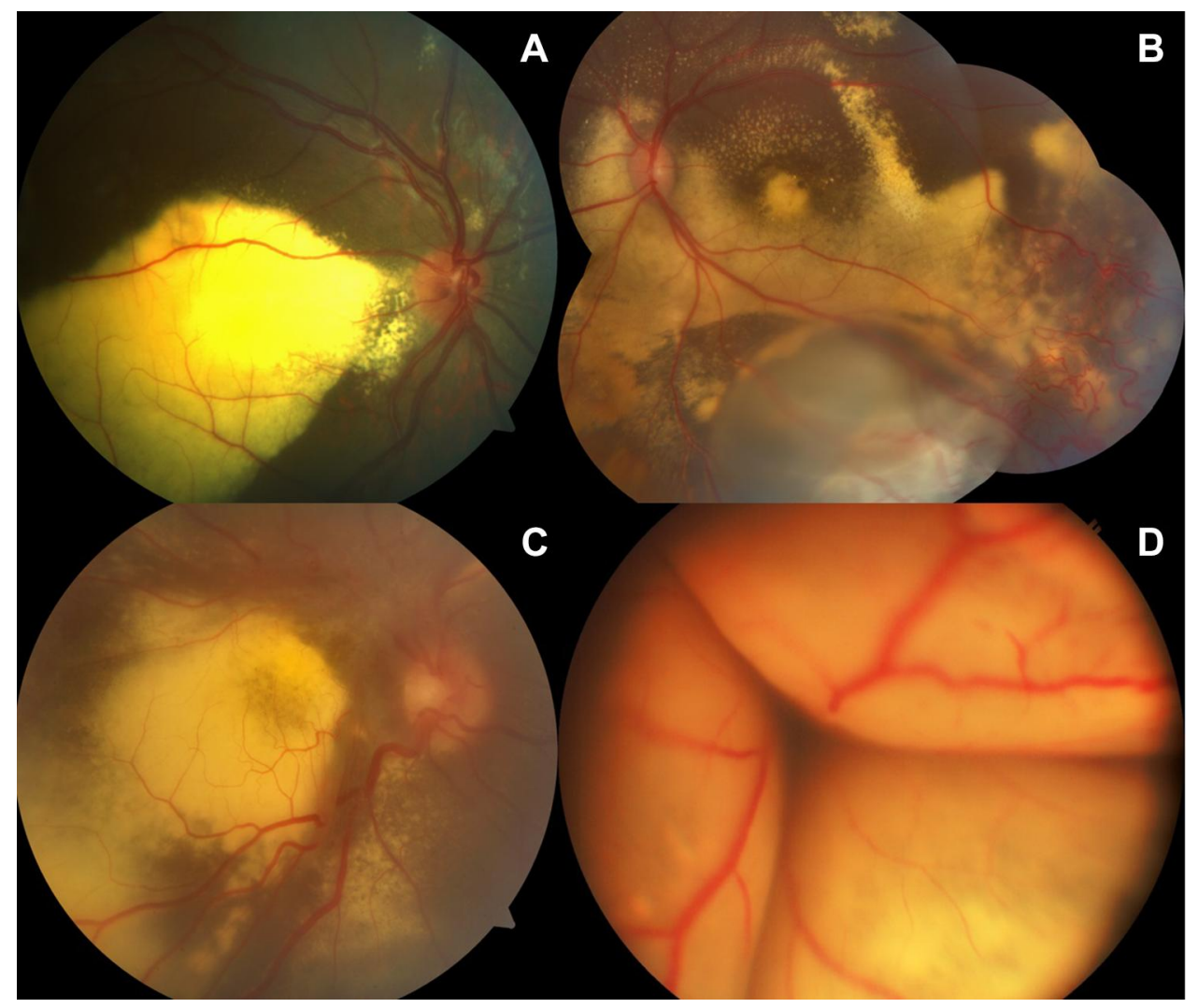

Figure I Colored fundus photographs of different stages of presentation from our analyzed patient sample of exudative Coats' disease, (A) stage 2B with telangiectasia and exudation involving the fovea, (B) stage 3AI with ERD not involving the fovea, (C) stage 3A2 with ERD involving the foveal region, and (D) stage 3B with total ERD taken by RetCam. 
Table I Intervention Type and Outcomes in Our Analyzed Sample of Exudative Coats' Disease $(n=16)$

\begin{tabular}{|c|c|c|c|c|c|c|}
\hline \multirow{2}{*}{ n (\%) } & \multicolumn{2}{|l|}{ Stage 2} & \multicolumn{3}{|l|}{ Stage 3} & \multirow[t]{2}{*}{ Total } \\
\hline & $2 A$ & 2B & 3AI & $3 A 2$ & 3B & \\
\hline \multicolumn{7}{|l|}{ Intervention } \\
\hline Anti-VEGF & $2(12.5)$ & $2(12.5)$ & $5(31.25)$ & $2(12.5)$ & $5(31.25)$ & $16(100)$ \\
\hline Cryotherapy & I (6.25) & $2(12.5)$ & $4(25)$ & $2(12.5)$ & $5(31.25)$ & $14(87.5)$ \\
\hline Laser ablation & $0(0)$ & I (6.25) & I (6.25) & $0(0)$ & $2(12.5)$ & $4(25)$ \\
\hline SRF drainage* & NA & NA & $0(0)$ & I (6.25) & $2(12.5)$ & $3(31.25)$ \\
\hline PPV or buckle & NA & NA & $0(0)$ & I (6.25) & $2(12.5)$ & $3(18.75)$ \\
\hline \multicolumn{7}{|l|}{ Outcome } \\
\hline Stabilization & $2(12.5)$ & $2(12.5)$ & $5(31.25)$ & $2(12.5)$ & $4(25)$ & $15(93.75)$ \\
\hline Progression & $0(0)$ & $0(0)$ & $0(0)$ & $0(0)$ & I (6.25) & I (6.25) \\
\hline Partial resolution & NA & NA & I (6.25) & I (6.25) & $2(12.5)$ & $4(25 \%)$ \\
\hline Complete resolution & $2(12.5)$ & $2(12.5)$ & $4(25)$ & I (6.25) & $2(12.5)$ & II (68.75) \\
\hline Complication & $0(0)$ & $0(0)$ & $0(0)$ & $0(0)$ & $3(18.75)$ & $3(18.75)$ \\
\hline
\end{tabular}

Note: *External trans-scleral drainage.

Abbreviation: NA, not applicable.

progressed from stage $3 \mathrm{~B}$ to stage 4 and then stage 5 , but enucleation was not required (blind painless eye). Complete resolution was seen in 11 cases $(68.75$, Figure $2)$. One patient $(6.67 \%)$ had VR fibrosis prior to any intervention. Retinal fibrosis developed in the remaining 15 cases post-intervention but was subretinal and stable in 12 patients $(80 \%)$. The remaining three cases $(20 \%)$ had VR fibrosis, one of which (33.33\%) had undergone PPV, but none progressed to develop TRD over the duration of follow-up.

Compared to pre-intervention, CDVA in the final follow visit improved in two patients $(22.22 \%)$, remained unchanged in 6 patients $(66.67 \%)$, and worsened in 1 patient (11.11\%). Two of the patients with unchanged CDVA had macular scarring from the long-standing exudation prior to any intervention.

\section{Discussion}

We report our experience in managing 16 eyes with exudative Coats' disease with intravitreal ranibizumab as an adjunct to ablation therapy. A favorable outcome was observed, with stabilization of the condition in $93.75 \%$ of the eyes and complete resolution in $68.75 \%$ of them. Progression was seen in only one eye and none required enucleation during the follow-up duration.

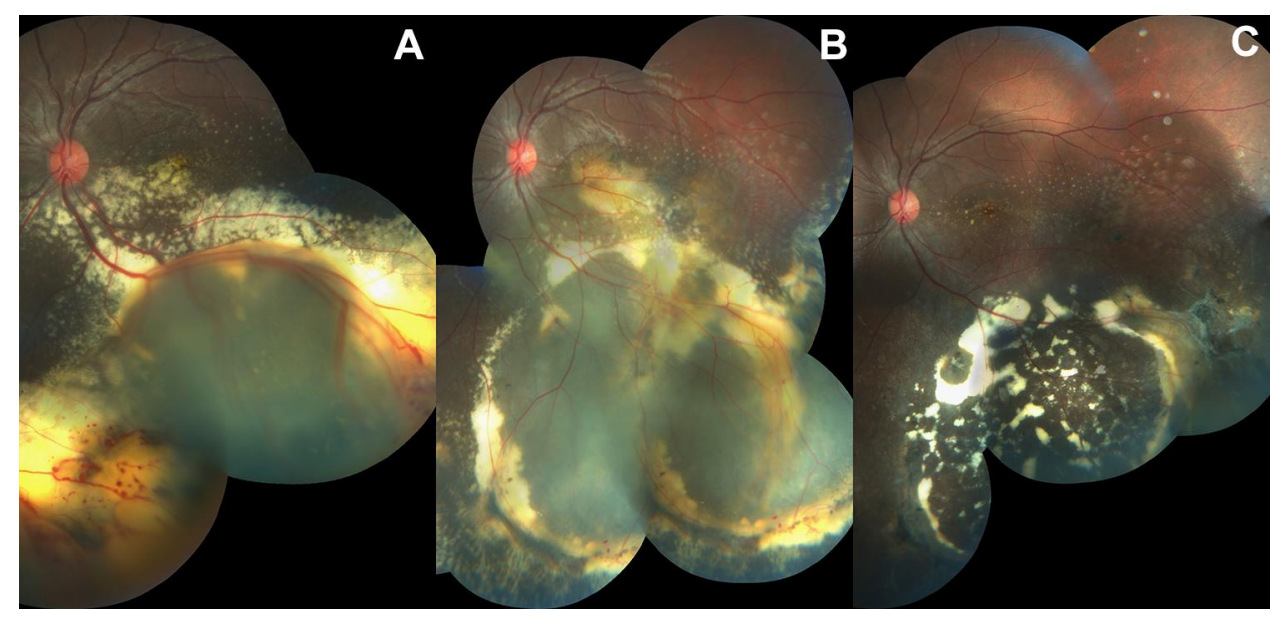

Figure 2 Colored fundus photographs of the left eye in a 13-year-old female patient with stage 3A disease. (A) Initial presentation (CDVA: 20/I00, 0.2), (B) follow-up I month following intervention with incomplete resolution of SRF, and (C) final follow-up after 13 months with complete resolution of SRF and telangiectasia, and marked reduction in exudate density (CDVA: 20/50, 0.4). Intervention was repeated once and consisted of laser ablation therapy and intravitreal ranibizumab. 
The demographic data of our patient group are similar to those reported in previous studies..$^{2,5,10,13}$ Most of our patients (12 out of 16) were stage 3 at the time of presentation, which is consistent with the report by Shields' et $\mathrm{al}^{5}$ in which stage 3 was found to represent $74 \%$ of the cases. Daruich et $\mathrm{al}^{14}$ have recently reported that the younger the age of the patient (specifically those below the age of 4 years), the higher the grade of the presentation. In our experience, only 5 of the 12 patients who were stage 3 were below the age of 4 years at the time of presentation.

Systemic association with Parry-Romberg syndrome was found in one of our patients. There are currently three cases reported in the literature with Parry-Romberg syndrome associated with Coats' or Coats-like disease, ${ }^{15-17}$ with our case being the fourth. There is also a case of Coats' disease reported in a series of patients with scleroderma en coup de sabre, another form of idiopathic hemifacial atrophy. ${ }^{18}$ Such an association between two very rare disease entities, both with unclear pathogenesis, suggests common-origin developmental defect.

Our results are in line with the recent chronological analysis $^{6}$ of Coats' disease that has highlighted more favorable outcomes in the latest decades with earlier management of the exudative forms of the condition. Intravitreal injection of anti-VEGF agents has strongly made its way into most of the recently suggested management protocols for exudative Coats' disease, particularly stage 3.,19-21 We report favorable and maintained outcomes with the combined use of the anti-VEGF agent, ranibizumab, and ablation therapy in our studied sample of 16 eyes. A similar experience by Li et $\mathrm{al}^{20}$ has demonstrated successful usage of intravitreal ranibizumab combined with ablation therapy in 17 eyes with stage 3 disease, with significant decrease in SRF and stabilization of the condition in all eyes. A variation between the two studies is that all patients in their cohort received laser therapy with only three undergoing additional cryotherapy, ${ }^{20}$ while most of our patients $(87.5 \%)$ underwent cryotherapy and only a quarter $(25 \%)$ underwent laser ablation.

Reviewing our results against some of the other studies that did not utilize anti-VEGF injection, Nucci et $\mathrm{al}^{22}$ retrospectively analyzed 32 eyes that had undergone laser ablation alone and found that only one eye required enucleation, but while the definition of successful therapy is outlined in the paper, the report on the success rate is missing. Mrejen et $\mathrm{al}^{23}$ reported on a heterogeneous combination of therapies in 15 eyes with Coats' disease, including laser ablation, cryotherapy, and VR surgery. Three of the eyes (20\%) developed phthisis bulbi and required enucleation. Ghazi et $\mathrm{al}^{24}$ reported on the successful use of intravitreal triamcinolone acetate injections followed by ablation therapy to decrease the incidence of subsequent VR fibrosis, but the report only included four eyes in total, two of which had persistent SRF, and three had a short follow-up interval of 1-4 months. In their recently reported 20-year experience with Coats' disease, Ong et $\mathrm{al}^{25}$ outlined more favorable outcomes with the addition of anti-VEGF agents to ablation therapy in the recent decades, especially in stage $3 \mathrm{~A}$. While we would be inclined to assert the superiority of anti-VEGF injection as an adjunct therapy, we believe such a question would be more suited to a well-controlled, prospective study.

Many surgeons promote drainage of SRF as an effective means to achieving resolution, especially in advanced disease. ${ }^{10,13,21}$ This could be carried out via an external transscleral approach ${ }^{13}$ or internally via PPV which has recently been reported by Ucgul et al $^{26}$ to have a superior outcome. In our experience, one of the three cases that underwent external SRF drainage had an iatrogenic break that required further intervention via PPV. However, PPV entails the transformation of the ERD to an RRD with a higher risk of VR fibrous proliferation. We, thus, recommend for SRF drainage to be reserved for advanced cases with high ERDs in which ablation treatment had failed or could not be carried out, and that when needed, external drainage would be more favorable.

Intravitreal anti-VEGF agents have conversely been suggested to increase the incidence of VR fibrosis and TRD when used for treatment of exudative Coats' disease. In the report by Ramasubramanian and Shields,${ }^{11}$ four of the eight patients treated with intravitreal bevacizumab and ablation therapy developed VR fibrosis, and three of them developed TRD within 9 months of injection. Gaillard et $\mathrm{al}^{12}$ also reported that five of the nine eyes treated with intravitreal ranibizumab and ablation therapy developed VR fibrosis, one of which progressed to develop TRD. On the other hand, Li et al ${ }^{20}$ reported no cases of VR fibrosis in their 17 studied eyes that underwent a median of three ranibizumab injections. In our experience, only 3 of our 16 eyes developed VR fibrosis and none progressed to TRD.

Our work is limited by the single-center, noncomparative, retrospective analysis of a relatively small sample size. It is imperative here to highlight that no systematic review or meta-analysis on the topic of managing Coats' 
disease has been reported to date. This is probably owing to the rarity of the condition, suboptimal retrospective reporting, heterogeneity in patients' characteristics and disease stage, varying therapeutic combinations, timing, and followup intervals, and unclear outcomes definition in the different reports. ${ }^{7}$ Future well-designed prospective studies - possibly through a global collaboration network - with pre-defined outcomes would be ideal.

In conclusion, we report our favorable experience with combining intravitreal ranibizumab injection and ablation therapy in managing exudative Coats' disease. We recommend for external SRF drainage to be preserved for eyes where ablation therapy is not feasible. We also highlight the lack of consensus and the controversy regarding the different treatment modalities utilized in managing Coats' disease, and stress on the need of well-designed, prospective, comparative studies.

\section{Disclosure}

The authors report no conflicts of interest in this work.

\section{References}

1. Yang X, Wang C, Su G. Recent advances in the diagnosis and treatment of Coats' disease. Int Ophthalmol. 2019;39(4):957-970. doi:10.1007/s10792-019-01095-8

2. Morris B, Foot B, Mulvihill A. A population-based study of Coats disease in the United Kingdom I: epidemiology and clinical features at diagnosis. Eye. 2010;24(12):1797-1801. doi:10.1038/eye.2010.126

3. Sigler EJ, Randolph JC, Calzada JI, Wilson MW, Haik BG. Current management of Coats disease. Surv Ophthalmol. 2014;59(1):30-46. doi:10.1016/j.survophthal.2013.03.007

4. Brockmann C, Löwen J, Schönfeld S, et al. Vascular findings in primarily affected and fellow eyes of middle-aged patients with Coats' disease using multimodal imaging. Br J Ophthalmol. 2020. doi:10.1136/bjophthalmol-2020-317101

5. Shields JA, Shields CL, Honavar SG, Demirci H, Cater J. Classification and management of Coats disease: the 2000 proctor lecture. Am J Ophthalmol. 2001;131(5):572-583. doi:10.1016/S00029394(01)00896-0

6. Shields CL, Udyaver S, Dalvin LA, et al. Coats disease in 351 eyes: analysis of features and outcomes over 45 years (by decade) at a single center. Indian $J$ Ophthalmol. 2019;67:772. doi:10.4103/ijo. IJO_449_19

7. Adeniran JF, Duff SM, Mimouni M, Lambert N, Ramasubramanian A. Treatment of Coats' disease: an analysis of pooled results. Int J Ophthalmol. 2019;12(4):668-674. doi:10.18240/ijo.2019.04.23

8. He Y-G, Wang H, Zhao B, Lee J, Bahl D, McCluskey J. Elevated vascular endothelial growth factor level in Coats' disease and possible therapeutic role of bevacizumab. Graefe's Arch Clin Exp Ophthalmol. 2010;248(10):1519-1521. doi:10.1007/s00417-010-1366-1

9. Ray R, Barañano DE, Hubbard GB. Treatment of Coats' disease with intravitreal bevacizumab. Br J Ophthalmol. 2013;97(3):272LP- 277. doi:10.1136/bjophthalmol-2012-302250
10. Liang T, Peng J, Zhang Q, Zhu X, Xu Y, Zhao P. Management of stage 3B Coats disease: presentation of a combined treatment modality and long-term follow-up. Graefe's Arch Clin Exp Ophthalmol. 2020;258(9):2031-2038. doi:10.1007/s00417-020-04739-Z

11. Ramasubramanian A, Shields CL. Bevacizumab for Coats' disease with exudative retinal detachment and risk of vitreoretinal traction. Br J Ophthalmol. 2012;96(3):356-359. doi:10.1136/bjophthalmol2011-300141

12. Gaillard M-C, Mataftsi A, Balmer A, Houghton S, Munier FL. ranibizumab in the management of advanced Coats disease stages $3 \mathrm{~B}$ and 4: long-term outcomes. Retina. 2014;34(11):2275-2281. doi:10.1097/ IAE.0000000000000248

13. Yousef YA, ElRimawi AH, Nazzal RM, et al. Coats' disease: characteristics, management, outcome, and scleral external drainage with anterior chamber maintainer for stage $3 \mathrm{~b}$ disease. Medicine (Baltimore). 2020;99(16):e19623. doi:10.1097/ MD.0000000000019623

14. Daruich A, Matet A, Munier FL. Younger age at presentation in children with Coats disease is associated with more advanced stage and worse visual prognosis: a retrospective study. Retina. 2018;38 (11):2239-2246. doi:10.1097/IAE.0000000000001866

15. Park DH, Kim IT. Patient with Parry-Romberg syndrome complicated by Coats' syndrome. Jpn J Ophthalmol. 2008;52(6):520-522. doi:10.1007/s10384-008-0597-8

16. Nasser O, Greiner K, Amer R. Unilateral optic atrophy preceding Coats disease in a girl with Parry-Romberg syndrome. Eur J Ophthalmol. 2010;20(1):221-223. doi:10.1177/ 112067211002000132

17. Agarwal A, Pilania RK, Anjani G, Choudhary H, Gupta A, Gupta V. Retinal vasculitis with coats-like response in a young girl with Parry-Romberg Syndrome. JCR J Clin Rheumatol. 2019. doi:10.1097/RHU.0000000000001052

18. Ullman S, Danielsen PL, Fledelius HC, Daugaard-Jensen J, Serup J. Scleroderma en Coup de Sabre, Parry-romberg hemifacial atrophy and associated manifestations of the eye, the oral cavity and the teeth: a Danish follow-up study of 35 patients diagnosed between 1975 and 2015. Dermatology. 2020. doi:10.1159/000507925

19. Grosso A, Pellegrini M, Cereda MG, Panico C, Staurenghi G, Sigler EJ. Pearls and pitfalls in diagnosis and management of coats disease. Retina. 2015;35(4):614-623. doi:10.1097/IAE.0000000 000000485

20. Li S, Deng G, Liu J, Ma Y, Lu H. The effects of a treatment combination of anti-VEGF injections, laser coagulation and cryotherapy on patients with type 3 Coat's disease. BMC Ophthalmol. 2017;17(1):76. doi:10.1186/s12886-017-0469-4

21. Mastropasqua R, D'Aloisio R, Stanga PE, Haynes R. Multiple therapy approach for stage 3 Coats disease: long-term follow-up. J Ophthalmol. 2020;2020:8840630. doi:10.1155/2020/8840630

22. Nucci P, Bandello F, Serafino M, Wilson ME. Selective photocoagulation in Coats' disease: ten-year follow-up. Eur $J$ Ophthalmol. 2002;12(6):501-505. doi:10.1177/112067210201200609

23. Mrejen S, Metge F, Denion E, Dureau P, Edelson C, Caputo G. Management of retinal detachment in coats disease. Retina. 2008;28:S26-S32. doi:10.1097/IAE.0b013e31816b3158

24. Ghazi NG, Al Shamsi H, Larsson J, Abboud E. Intravitreal triamcinolone in Coats' disease. Ophthalmology. 2012;119(3):648-649.e2. doi:10.1016/j.ophtha.2011.09.059

25. Ong SS, Buckley EG, McCuen BW, et al. Comparison of visual outcomes in Coats' disease. Ophthalmology. 2017;124 (9):1368-1376. doi:10.1016/j.ophtha.2017.03.051

26. Ucgul AY, Ozdek S, Ertop M, Atalay HT. External drainage alone versus external drainage with vitrectomy in advanced Coats' disease. Am J Ophthalmol. 2020;222:6-14. doi:10.1016/j.ajo.2020.09.006 


\section{Publish your work in this journal}

Clinical Ophthalmology is an international, peer-reviewed journal covering all subspecialties within ophthalmology. Key topics include: Optometry; Visual science; Pharmacology and drug therapy in eye diseases; Basic Sciences; Primary and Secondary eye care; Patient Safety and Quality of Care Improvements. This journal is indexed on PubMed

Submit your manuscript here: https://www.dovepress.com/clinical-ophthalmology-journal
Central and CAS, and is the official journal of The Society of Clinical Ophthalmology (SCO). The manuscript management system is completely online and includes a very quick and fair peer-review system, which is all easy to use. Visit http://www.dovepress.com/ testimonials.php to read real quotes from published authors. 